\title{
Artelogie
}

Recherche sur les arts, le patrimoine et la littérature de I'Amérique latine

16 | 2021

Fotografía y migraciones, siglos XIX-XXI.

\section{Imágenes migrantes. La memoria migratoria en el fotoarte de Juan José de Jesús Yas (Kohei Yasu 1844-1917)}

Néstor Felícito Véliz Catalán

\section{OpenEdition}

Journals

Edición electrónica

URL: https://journals.openedition.org/artelogie/8911

DOI: 10.4000/artelogie.8911

ISSN: 2115-6395

Editor

Association ESCAL

Referencia electrónica

Néstor Felícito Véliz Catalán, «Imágenes migrantes. La memoria migratoria en el fotoarte de Juan José de Jesús Yas (Kohei Yasu 1844-1917)», Artelogie [En línea], 16 | 2021, Publicado el 27 enero 2021 consultado el 03 septiembre 2021. URL: http://journals.openedition.org/artelogie/8911 ; DOI: https:// doi.org/10.4000/artelogie.8911

Este documento fue generado automáticamente el 3 septiembre 2021.

Association ESCAL 


\title{
Imágenes migrantes. La memoria migratoria en el fotoarte de Juan José de Jesús Yas (Kohei Yasu 1844-1917)
}

\author{
Néstor Felícito Véliz Catalán
}

\section{Introducción}

1 Este artículo presenta, en primera instancia un resumen de los principales datos biográficos de Kohei Yasu, un astrónomo y viajero japonés que se residenció casi ininterrumpidamente en Guatemala entre 1877 y 1917. Seguidamente, se establece cuál fue el panorama político del país al momento de su llegada e inserción, enfatizando en que, recientemente, se habita instalado un nuevo equilibrio de poder en el que habían accedido a sitial hegemónico grupos emergentes de ideología liberal, cuyas políticas favorecieron la migración.

2 En este artículo se presenta también el análisis de las condiciones en que, Yasu, (desde 1878 Juan José de Jesús Yas, tras su conversión al catolicismo) irrumpe en un medio extraño y hasta cierto punto hostil para forjarse una brecha como artista y especialista de la fotografía artística. En un país como Guatemala, el hecho de ser asiático le condicionaba y colocaba en una posición de cierta desventaja, lo que compensó con el desarrollo de grandes talentos que le permitieron acuñar un sello particular a los productos de su trabajo en el estudio "Fotografía Japonesa", heredado después de su fallecimiento ocurrido en 1917 a su ahijado y sobrino político José Domingo Noriega, quien lo sostuvo hasta bien entrado el siglo XX.

3 Este fue el marco contextual en el que él desarrolló una labor pionera en el ejercicio de la fotografía artística sobre diversos objetos que captaron su atención. Entre los principales elementos cuya apariencia posterizó están los siguientes: edificios e imágenes religiosas, funcionarios civiles y religiosos y, muy particularmente de interés 
para el presente trabajo, testimonios de una memoria migratoria matizada por la experiencia personal como viajero y profesional de la fotografía.

\section{Introduciéndonos a la vida de Kohei Yasu: aspectos biográficos}

\subsection{Un personaje enigmático más que poco conocido}

4 Kohei Yasu o, como se hizo llamar desde 1878, Juan José de Jesús Yas ${ }^{1}$ es una figura versátil, sobre la cual no se ha escrito mucho en el país donde vivió la segunda mitad de su vida, se casó y ejerció el oficio de fotógrafo. En el contexto guatemalteco, a la fecha (2020), son sumamente escasos los estudios que, en forma de artículo o ensayo, se focalicen completamente en su legado. Es mucho más frecuente su citación como referente de la fotografía, como profesión u oficio emergente a fines del siglo XIX e inicios del XX. Esta mención se hace de una forma complementaria a explicaciones sobre el desarrollo de la fotografía en el país, sin mayor interés en los aspectos migratorios, discursivos o estéticos de su trabajo, siendo esto frecuente en algunos trabajos de graduación recientes.

5 Este es el tenor de dos trabajos consultados por la antropóloga taiwanesa Pi-Heng Chen, donde el historiador guatemalteco Luis Luján Muñoz se explaya sobre su contribución a la fotografía de Antigua Guatemala, enfocándose también en el aporte de su sobrino político, el también fotógrafo José Domingo Noriega ${ }^{2}$. Estos trabajos constituyen aportaciones desde diversos posicionamientos metodológicos que permiten la apreciar la magnitud de la obra fotográfica de Yasu y su comprensión como un legado con proyecciones estéticas y documentales. ${ }^{3}$

6 Si se intenta hacer de él una caracterización, le puede tomar como astrónomo y fotógrafo, así como uno de tantos "viajeros" que en el siglo XIX, sujetos ilustrados con una aureola cosmopolita y pulsión por explorar el mundo que hasta entonces permanecía desconocido con ojos atentos a "descubrir" paisajes y escenas insólitas en tierras desconocidas, lejanas, lo cual, muchas veces quedó grabado para la posteridad en la fotografía. Es en este sentido, que su contribución al fotoarte guatemalteco resulta sumamente importante, pues constituye una figura de renombre para la segunda generación de fotógrafos profesionales en el país y además proviene, como otros iniciadores de la fotografía, de fuera del país, proveniente de otra matriz cultural.

7 Pese a las barreras entre la cultura japonesa y la española que se implantó tras tres siglos de coloniaje, en Guatemala se ha desarrollado una forma particular de orientalismo japonista o "japonismo" en el notorio literato Flavio Herrera (1895-1968), quien publicó muchos "hai-kais", poemas con similar estructura y extensión que los clásicos haikus. Este interés en Japón también existió en el periodista y escritor Enrique Gómez Carrillo (1873-1921), conocido como el "Príncipe de la Prosa", quien publicó un volumen de narrativa titulado "El Japón heroico y galante", obra de culto al contexto que caracterizaba a Japón antes de las Reformas Meiji. Podría concluirse que, la inmersión de Yasu en la religiosidad y arquitectura religiosa guatemaltecas es parte de los intercambios culturales iniciados con la obra de Gómez Carrillo.

\subsection{Primeros años y juventud}

Este fotógrafo nació en Japón durante el reinado del Emperador Komei, existiendo varias versiones sobre la fecha de su nacimiento. En algunas fuentes, se consigna que 
nació en 1844, un 27 de diciembre, mientras que en otras, nació a principios de julio de 1856. Lo que no se discute tanto es el lugar donde vio la luz primera, la ciudad de Fujisawa en la actual prefectura de Iwate, al norte de la isla de Honshu u Hondo, la central y mayor del archipiélago nipón. Su padre, Shoan Yasu, un médico tradicional, le envió a los 15 años a estudiar medicina con un tío a Tokio. Luego, dos años después, en Yokohama estudiaba medicina oriental, francés y Astronomía y viajaba a Kyoto y Kochi.

El despuntar a la adultez de Yasu coincidió con un conflicto que convulsionó Japón, del cual el país saldría orientado a una forma particular de modernización, dejando atrás las viejas estructuras económicas y políticas, cuestionadas ya desde el momento mismo de la apertura del país al comercio con los países europeos y Estados Unidos de Norteamérica. En enero de 1868, tuvo inicio la llamada "Guerra Boshin", iniciada por la oposición a las Reformas Meiji. Estas medidas, implementadas desde el poder por el nuevo Emperador, dejaron sin poder de los señores feudales o daimios, privatizaron la tierra y desmovilizaron a los ejércitos samuráis, trastocando un ordenamiento socioeconómico milenario. Kohei participó en ella cuando se enlistó en las tropas oficiales como médico militar y sirvió hasta el término de la campaña, en septiembre. ${ }^{4}$

10 Al concluir el conflicto se trasladó a Yokohama con un hermano menor, con quien asistió a una escuela dirigida por maestros franceses donde aprendió castellano y depuró su francés. Su hermano falleció en 1873, a la temprana edad de 17 años. Posiblemente, afectado por esta muerte, decidió viajar fuera de Japón un año después. Dicha resolución coincidió el arribo al país de varias comisiones de científicos franceses, mexicanos y estadounidenses llegaron para observar ahí el tránsito de Venus frente al Sol, acontecimiento astronómico que convocó a muchos interesados alrededor del mundo por aquellos años.

11 El grupo de mexicanos, dirigido por Francisco Díaz Covarruvias (1833-1889) se instaló en el puerto de Yokohama, sirviendo ahí Yasu de intérprete por su dominio del castellano, desarrollando mucha empatía hacia ellos, lo que derivó en un gran interés por viajar a Occidente. A tanto llegó su acoplamiento con estos científicos, que pidió al líder del mismo llevarle a México para iniciar con profundidad estudios de astronomía, a lo que el mexicano accedió.

12 Según un diario de Kohei que se conserva en un archivo histórico de su ciudad natal, al cumplir 29 años, abandonó Japón en un viaje motivado por las observaciones astronómicas realizadas por las comisiones en que se insertó a través de su labor como traductor, lo que le llevaría a otros lugares desconocidos. Estos datos se encuentran insertos en un documento consultado por Pi-Heng Chen, resguardado en la colección "Kohei Yasu" Fujisawa, Centro Cívico de la Ciudad de Ichinoseki, prefectura de Iwate, Japón. Asimismo, el periodista guatemalteco José Luis Escobar incluyó algunas citas del mismo en un artículo periodístico publicado en 2017, en el cual no se incluyen referencias del origen de la información.

13 El día 2 de febrero abandonó su país embarcándose en Yokohama, llegando a Europa por el Mediterráneo tras varias escalas. ${ }^{5}$ Permaneció en el continente hasta los últimos días del verano. El 18 de septiembre partió hacia América desde las Islas Azores, en el Atlántico y llegó a Veracruz tras casi diez meses de navegación. Desde ahí se dirigió a la ciudad de México, a donde llegó el 18 de noviembre de 1875 para empezar sus estudios de Astronomía a inicios del año siguiente. 

poder capitalinos, llegando a presentarlo al entonces presidente, Sebastián Lerdo de Tejada, sucesor de Benito Juárez a su muerte en 1872. A mediados de 1876, tuvo lugar un alzamiento del general oaxaqueño Porfirio Díaz, el cual, cobrando fuerza, obligó a salir al mandatario de la ciudad capital; dicha facción liberal tomó el poder y los allegados de Lerdo de Tejada, antes de que iniciara una persecución general, arreglaron la salida de Yasu como ministro plenipotenciario hacia Guatemala.

\section{Un japonés en la Guatemala liberal}

\subsection{Arribo a Guatemala e instalación en un nuevo espacio} entonces, estaba gobernado por el General Justo Rufino Barrios y Auyón (1835-1885), en sus inicios abogado y terrateniente liberal que tomó el poder derrotando a las milicias del presidente conservador Vicente Cerna en alianza con una fracción de la oligarquía tradicional, el también general Miguel García Granados (1809-1875).

Ambos líderes estuvieron grandemente influidos por el ideario político de la Reforma Liberal Mexicana, al punto de replicarla en el país tras su triunfo en una guerra interna $\mathrm{y}$, una vez en el poder, difundir e imponer los principios liberales por varias naciones de Centroamérica. ${ }^{6}$ El breve gobierno del primero (1871-1873), sirvió de antesala al despliegue del poder absoluto de Barrios, dirigente militar de la Reforma, quien actuó como dictador hasta su muerte, ocurrida en un confuso incidente ocurrido en abril de 1885, cuando se disponía a realizar una invasión militar a El Salvador como parte de su campaña para unificar a Centroamérica bajo su mando. Desde esa posición, impuso cambios que afectaron profundamente la administración pública, educación, economía y cultura, lo que le ganó el título, para la posteridad de "El Reformador".

Desde su triunfo, en 1871, los liberales procedieron a la realización gradual de su plan de reformas, en cuyo cumplimiento atacaron frontalmente los intereses de las órdenes religiosas y las comunidades indígenas. Desde ese año, se expropiaron los bienes clericales, se procedió a la conformación de un mercado de tierras con base en ofertar muchas propiedades comunales respetadas por los conservadores y se establecieron disposiciones legales que reactualizaban el trabajo forzado. mayorías, ya que los conservadores habían reinstalado en el largo gobierno de Carrera las formas de tutela y control social vigentes durante la época colonial, obteniendo la adherencia y simpatía de los indígenas, afectados antes por los intentos reformistas de los grupos liberales que trajeron medidas tributarias perjudiciales para sus intereses, tal como sucedió con la política fiscal y de expropiación de las tierras comunales.

La Reforma Liberal guatemalteca se enmarca en los intentos de las élites por modernizar al país reemplazando la hegemonía oligárquica-clerical, propia del período de gobierno conservador (1838-1871) por la de los sectores emergentes, de orientación progresista. Anteriormente, entre 1824 y 1838, dichas reformas fueron aplicadas con escaso éxito por grupos liberales, lo que provocó la oposición de los conservadores. Debido al escaso desarrollo de las condiciones objetivas para la industrialización y la participación en el contexto capitalista, esta alianza de sectores liberales no generó una intelligentsia burguesa como sucedía en las naciones avanzadas de Europa, sino que 
orientó las relaciones de producción del tipo que algunos autores denominan como "capitalismo agrario" y a la apelación dictatorial como mecanismo rector del control social y la generación de condiciones para la exportación del café.

El país permanecía, a la llegada de Kohei Yasu en 1877, en el sentido infraestructural, tal como lo encontró la independencia de $1821^{7}$, con una población mayoritariamente indígena, casi completamente rural y analfabeta, dependiente de la agricultura minifundista o de subsistencia, únicamente presentando como novedad la orientación a la exportación cafetalera promovida por el gobierno que trajo consigo capitales alemanes. Internamente, el Estado era gestor de los intereses cafetaleros, dictando la legislación agraria y laboral que permitía el funcionamiento del circuito de fincas, nutriéndolas de fuerza de trabajo indígena y mestiza, haciendo que la economía gravitara sobre la producción y exportación intensiva del grano.

Yasu, proveniente de México, arribó al país desde el puerto de San José, situado en el sureño departamento de Escuintla. Debido a la carencia de ferrocarriles ${ }^{8}$, hizo su arribo a la ciudad de Nueva Guatemala de la Asunción, situada aproximadamente a 100 kilómetros al norte a lomo de caballo. Al llegar, estableció la legación mexicana del gobierno en el exilio a fines de 1877 en una propiedad de Venancio Barrios, hijo del presidente de la República ${ }^{9}$, la cual estuvo ubicada en la esquina en que el Mercado Central colindaba con la calle de Santa Rosa, lo que corresponde a la actual $10^{\mathrm{a}}$ calle de la zona $1 .^{10}$

La llegada del japonés coincidió con el arribo de otros intelectuales de tendencia liberal, entre ellos, destacaba el revolucionario, escritor y poeta cubano José Martí y Pérez (1853-1895), proscrito por las autoridades españolas, así como sus paisanos José María Izaguirre, docente que fundó un colegio, y el poeta José Joaquín Palma (1844-1911), años más tarde ganador de un concurso para escoger la letra del Himno Nacional organizado por la Sociedad Literaria "El Porvenir". ${ }^{11}$ En aquellos momentos, la intelectualidad de vanguardia fue valorada como élite dirigencial, pues 1 presidente Barrios también acogió al joven intelectual hondureño Marco Aurelio Soto, a quien nombró Ministro de Educación Pública.

\subsection{Encontrando un "nicho" en la sociedad guatemalteca}

Kohei Yasu fue el primer inmigrante japonés registrado en Guatemala y podría decirse que también de Centroamérica. Anteriormente, la migración de nacidos en el Extremo Oriente se había concretado en el arribo de algunos chinos, los que se habían hecho presentes desde hacía tiempo en los puertos de la vertiente pacífica, insertándose algunos al comercio ${ }^{12}$. A su llegada, posiblemente no contempló ningún plan de permanencia, como correspondía a su calidad de improvisado diplomático. Debido a que, el status de cónsul del gobierno de Lerdo de Tejada no pudo continuar con el asentamiento de Porfirio Díaz, hubo de buscar otras fuentes de recursos para sobrevivir desde 1878.

24 Es en este entonces donde el astrónomo y viajero da lugar al fotógrafo en potencia y es cuando se inserta como asistente de Emilio (Emil) Herbruger, dueño del establecimiento "Centro Fotográfico". Debido a sus dificultades económicas, se insertó en el personal de este, iniciando como aprendiz y asistente, sacrificándose en grado sumo, puesto que trabajó casi sin remuneración a cambio de adquirir conocimientos en la labor ${ }^{13}$. 

Guatemala sin recalar en los precedentes del desarrollo de la fotografía en Guatemala. Aunque él provenía ya de un Japón abierto a la influencia occidental, en el que pioneros como el británico de origen italiano Felice Beato desarrollaban la fotografía y el grecobritánico Lafcadio Hearn se dedicaban a la divulgación de los aspectos culturales del país por medio de la prensa y la literatura, y que, desde años atrás era objeto de interés del lente de afamados fotógrafos e ilustradores como Beato, no aprendió el arte fotográfico en su país. fotografía en Guatemala, presenta los nombres de los pioneros de la fotografía en el país. Como sucedía en la región, muchos de ellos eran extranjeros, -europeos y estadounidenses- y se establecían en los países de habla castellana precedidos por el impulso de los adelantos tecnológicos propios de la Segunda Revolución Industrial y estimulados por las potencialidades de los mismos como mercado del nuevo arte.

En aquel tiempo, la fotografía estuvo reservada para el uso exclusivo de las élites, que le tenían como signo de status. Muchos de los apellidos de aquellos primeros fotógrafos revelan un origen foráneo, si bien los nombres propios tendieron siempre a castellanizarse: Manuel Oliver, presumiblemente francés, retratista con la técnica de daguerrotipo y Agustín Someliani, italiano y la sociedad de fotógrafos estadounidenses Fitzgibbon \& Buchanan, el segundo de ellos el primero en ejercer la profesión en Guatemala.

Con base en los aportes de Arturo Taracena Arriola, esta autora también establece como uno de los primeros fotógrafos guatemaltecos José Lara Corzo y el quetzalteco J. Doroteo González, activo para la década de 1860 en la región de los Altos. En la principal ciudad de esta región, Quetzaltenango, ejerció el oficio Tomás Zanotti, de obvia filiación italiana como Someliani.

31 Cuando Yasu abandonó la breve carrera diplomática iniciada en México, pronto se relacionó con funcionarios clericales guatemaltecos, fuertemente presionados en aquel entonces por el gobierno de Justo Rufino Barrios. Es posible que hayan tenido en él, un completo extraño, a alguien de confianza, debido al recelo que se tenía de simpatizantes del barrismo, la versión local del liberalismo radical en el poder. Después de 1877, se vinculó al religioso Angulo Urruela, quien se convirtió en su padrino cuando 
lo indujo a bautizarse y convertirse al catolicismo, adoptando el nombre de Juan José de Jesús Yas, lo que le dio una resonancia guatemalteca, concretamente, indígena.. ${ }^{15}$

En tiempos de su arribo, florecía en Guatemala un fotógrafo alemán, Emilio (Emil) Ernest Herbruger Rietsbrock, miembro de una familia dedicada a la fotografía, pues su padre, Emilio (Emil) Herbruger Wheling, de origen mixto (alemán-estadounidense) le heredó el estudio "Fotografía Central" en 1871. Los descendientes de esta familia se integraron a las élites políticas guatemaltecas, como se aprecia en el caso de Arturo Herbruger Asturias, abogado y legislador, vicepresidente entre 1993 y 1996, y Jorge Méndez Herbruger, presidente del Congreso de la República durante 1996 y el año 2000. El japonés, recién llegado y carente de otros recursos para sobrevivir, se hizo alumno de este, iniciando un proceso de aprendizaje y especialización que duraría varios años. Con el tiempo, este cúmulo de experiencias le llevaría a imprimirle a su trabajo un sello personalísimo, marcado por las circunstancias y singularidades que reunía el hecho de ser un asiático trasplantado a Guatemala. Vivió un tiempo con Covarrubias, también asilado en la ciudad. En las vecindades donde se alojaban existía el estudio "Centro Fotográfico", propiedad de Emilio Herbruger, con quien intercambió trabajo a cambio de conocimientos, padeciendo grandes privaciones, puesto que no recibía remuneración.

34 Una vez enfilado en el aprendizaje, y al no recibir aumento de salario tomó una determinación radical. Abandonó a los Herbruger, pasando a ser socio de Eduardo Kildare, quien había adquirido un establecimiento propiedad del estadounidense Walfestein, el cual sería el lugar en el que Yas iniciaría a desarrollar su arte con gran originalidad.

\subsection{La “Fotografía Japonesa en Guatemala” (1880-1959)}

Con Herbruger hijo, Yas aprendió las técnicas básicas para tomar fotografías en un período de aprendizaje que Taracena establece duró entre el año de su llegada y, posiblemente 1887. Una vez suficientemente capacitado, como se supone habrá llegado a estar en al menos nueve años de asistente tanto de Herbruger padre como de Kildare, se independizó fundando un estudio propio al que bautizó como "Fotografía Japonesa" en el año de $1880 .^{16}$

Como puede deducirse del nombre del estudio, Yas preservó el gentilicio originario para el espacio donde realizaba su trabajo, registrando una marca personal en el naciente universo de la fotografía guatemalteca, monopolizado por especialistas europeos. Su técnica para realizar fotografías sirviéndose de una capa de gelatina sobre el cristal es reconocida como un aporte original.

Yas trasladó el estudio en cuestión hacia la ciudad de Antigua Guatemala, antigua sede de la gobernación colonial en 1895. Pellecer afirma, basándose en datos consignados en medios periodísticos, que en marzo de 1909, el estudio de Yasu pasó a ubicarse en la $6^{\mathrm{a}}$ avenida Norte, en el No. 48. Este dato es sumamente importante, debido a que esta ubicación debió tener en el momento de ocurridos los terremotos de finales de 1917 e inicios de 1918, años en los que, tanto la ciudad capital como esta urbe, -en la que todavía se encontraban algunas edificaciones de la época colonial-, sufrieron daños considerables. Yas no presenció estos siniestros, ya que falleció principiando el año, el día 28 de febrero de 1917. 

aún espera por nuevas revisiones y exámenes para su incorporación al patrimonio histórico y estético del país. A través de procesos de investigación como los realizados por Pi-Heng Chen, se puede difundir no solamente el legado en sí mismo, que es desconocido por la gran mayoría de guatemaltecos, sino que también, el mismo puede generar ejercicios interpretativos efectuados bajo diversos parámetros y posicionamientos metodológicos, teóricos y discursivos.

\section{Fotoarte y memoria migratoria en Juan José de Jesús Yas}

\section{La fotografía como producto social y fuente de memoria}

Para la moderna Historia Ciencia y otras disciplinas socio humanísticas, la fotografía tiene gran importancia como elemento documental y testimonial. En el caso de la Historia, en el siglo XIX, el positivismo valoró grandemente el papel de la historiografía como narrativa de la realidad, lo cual se vio complementado por la representación de lo visual como discurso que permitía conocer los hechos presentándolo a la vista de los interesados tal y como "aparecían" ante los sentidos, siendo la vista un canal que permitía constatar la veracidad de los mismos.

A este respecto, conviene hacer una precisión: una fotografía no puede tener el carácter de elemento testimonial, material útil para documentar el pasado solamente por, sino que ello depende de las múltiples lecturas que la misma tenga en sus receptores $u$ observadores. En dicho sentido, puede afirmarse que la fotografía también puede ser tomada como producto social, por ser concreción, en su materialidad, de múltiples procesos, cuya secuencia y participación no son perceptibles en el momento de la observación, pero que pueden encontrarse concatenados a través del análisis y la reflexión. $^{18}$ 
La lógica de la producción capitalista, tomando un posicionamiento inclusivo con respecto a la Economía Política, lleva a entender a las mercancías como el resultado de necesidades sociales, así como de procesos de trabajo e intercambio que trajo consigo la entrada en el sistema capitalista de manos de la Reforma Liberal. Entendiendo que, la fotografía se deriva de un conjunto de cambios en los que la ciencia y técnica permiten la incorporación de la electricidad y procesos químicos a la captura de imágenes, también constituye, hablando en clave marxista, un salto cualitativo en el desarrollo tecnológico de la Humanidad ${ }^{19}$.

4 En dicho sentido, las generaciones que lo presencian, asisten a un momento en el que el hombre "captura" una imagen y preserva dicha representación en el tiempo a través de la conservación de su soporte impreso, lo que en la era digital se prolonga debido a que, una copia de imágenes impresas, un formato virtual o electrónico, exime a las imágenes de intervenciones del ambiente. No obstante, cuando los materiales han sido objeto de apropiaciones institucionales, el cuidado de fotografías en formato físico y los negativos requieren de la contratación de personal especializado y desembolso en la conservación.

Hechas estas previsiones, de rigor cuando se formula la concepción de la fotografía como un producto social, conviene establecer en qué radica la especificidad de la fotografía o el fotoarte que construye la memoria migratoria, construyendo lo que Alejandro Zarur Osorio denomina como la "imagen de la migración". Entonces, por así decirlo, la fotografía constituye un "rescate de la memoria" en el momento de ser efectuada, y en el futuro, un elemento que la construye proyectándose a otras generaciones, puesto que, sin memoria no existe identidad ni medios para construirla.

47 La fotografía es un elemento que también permite construir la memoria en los observadores, por cuanto cabe la posibilidad de que los mismos se identifiquen con su contenido. Si el mismo resulta significativo y logra provocar un anclaje en quien observa, tiene lugar el inicio de un proceso de identificación con los elementos contextuales que permiten generar sentimientos y percepciones de pertenencia.

1. 1. Ejemplos de la fotoarte en que se expresa la memoria migratoria en el fotoarte de Juan José de Jesús Yas

De entre las numerosas creaciones del arte fotográfico de Yas conservadas a la fecha, existen dos que destacan como muestras del fotoarte que recrea y construye a memoria migratoria. Es necesario comprender que esta modalidad representativa se dio de forma espontánea, no planificada, y que constituye uno de los aspectos de proyección de Yasu como fotógrafo, artista y a la vez migrante..$^{20}$ 


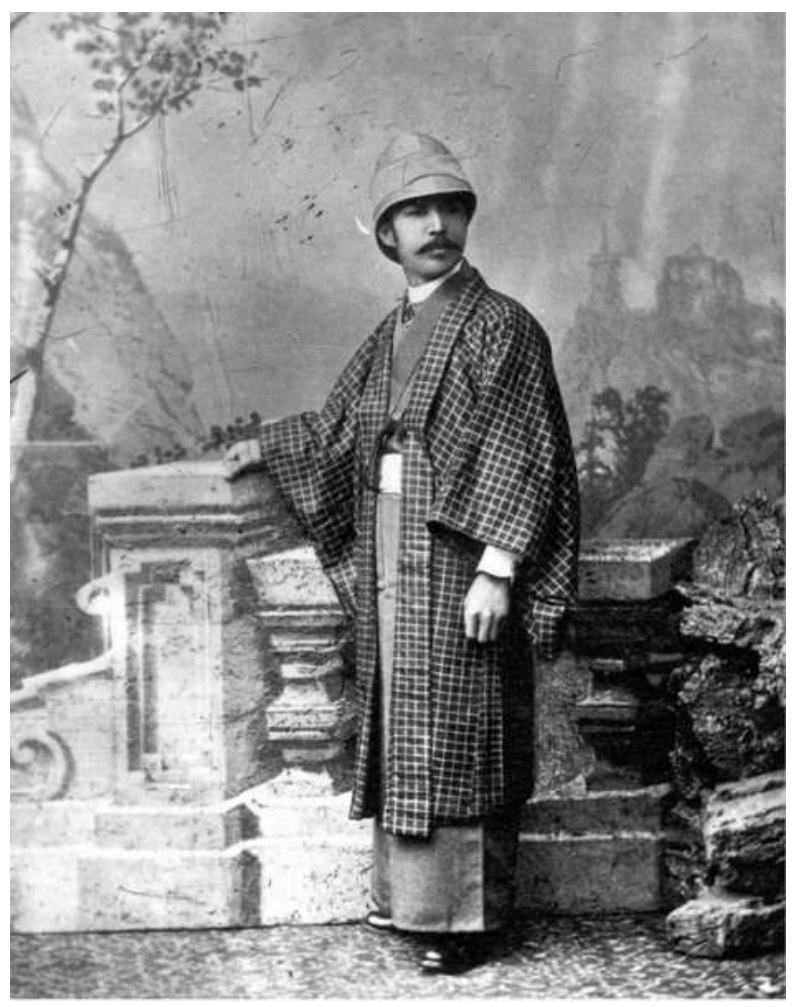

Figura 1: Retrato de cuerpo entero de Juan José de Jesús Yas, c. 1890.21 Carlos Eduardo Zeceña Alcayaga, CIRMA, Antigua Guatemala.

Link web: https://www.prensalibre.com/revista-d/el-legado-fotografico-de-juan-jose-de-jesus-yas/

José de Jesús Yas, se encuentra una en la que fue retratado de cuerpo entero, realizada obviamente por otro fotógrafo, aproximadamente en 1890. La imagen tiene la particularidad de presentarle con un atuendo en el que se muestra la simbiosis cultural que caracteriza su experiencia como fotógrafo, ciudadano de países tanto de Oriente como de Occidente y viajero. conforman su atuendo. De la cabeza a los pies, se encuentra en él que la mezcla de elementos orientales y occidentales deriva una especie de travestismo involuntario, pues de la misma forma en que se cubre la cabeza con un salacot al estilo de los legionarios franceses, se enfundó en un kimono que resulta más discreto al ser disimulado bajo una bata japonesa. El calzado oriental se ha perdido, pues Yas adoptó la moda europea.

La decoración de fondo asume un acento parcialmente oriental, mostrando árboles de ramas con una formación característica de los existentes en los bosques japoneses, empequeñecidos a través del arte del bonsái. También este fondo presenta una confluencia entre las culturas japonesa y europea occidental, apoyando Yas su brazo derecho en una pequeña columna de diseño grecorromano, la cual constituye la terminación de una barda que consta de un par de columnatas que incluyen diseños en forma almohadillada.

52 En esta toma, Yas se hizo fotografiar luciendo un espeso bigote, moda en boga entonces en Europa y América, tendencia adoptada en Japón por funcionarios militares en la era Meiji. El talante de la postura que tomó es también interesante, presentando una 
posición confiada, serena, lo que puede evidenciar un aprendizaje para posar adquirido en sus años de asistente en el estudio de Emilio Herbruger hijo. ${ }^{22}$

Esta fotografía, en su conjunto, es una muestra de la personalidad del fotógrafo, la cual tiene una proyección a ambos mundos, el nativo y el que encontró al decidirse viajar con la expedición astronómica dirigida por Covarrubias. La misma lo muestra como un hombre al día, convencido de que Japón, para participar en el concierto de las naciones civilizadas, hubo de abrirse a la influencia occidental y que también, Occidente alcanza la dimensión global de sus usos, tradiciones y forma de concebir al mundo cuando domeña y vence las resistencias de países que, como el Imperio del Sol Naciente, se habían "cerrado" a cualquier intercambio, permaneciendo en aislamiento del movimiento comercial internacional.

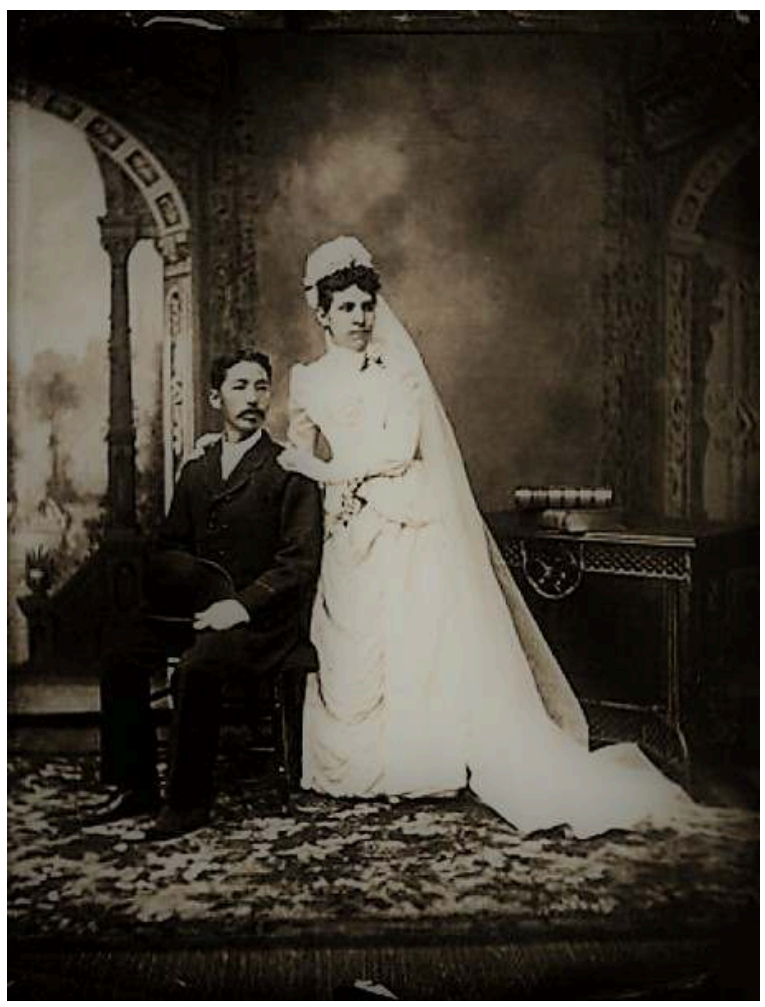

Figura 2: Fotografía tomada poco después del matrimonio entre Juan José de Jesús Yas y María Noriega en 1891. ${ }^{23}$ Carlos Eduardo Zeceña Alcayaga, CIRMA, Antigua Guatemala.

Link web: https://www.prensalibre.com/revista-d/el-legado-fotografico-de-juan-jose-de-jesus-yas/

La fotografía de la boda de Yas con María Noriega en 1891 también es otro testimonio que muestra la personalidad ambivalente, en el sentido cultural, del fotógrafo. Esta imagen le retrata ya como un ciudadano de un país occidental, plenamente identificado con los usos y el vestuario en boga, ciudadano de un país que aspiraba a la modernidad a través de la Reforma Liberal. Esto quedó plasmado gráficamente, donde se le encuentra posando con su esposa después de haber contraído matrimonio como lo mandan tanto las Leyes como la Iglesia, que a pesar del anti-clericalismo liberal, no manifestaba valores totalmente incompatibles con los dictámenes del gobierno laico que hizo de la secularización de los espacios públicos una política de Estado. 


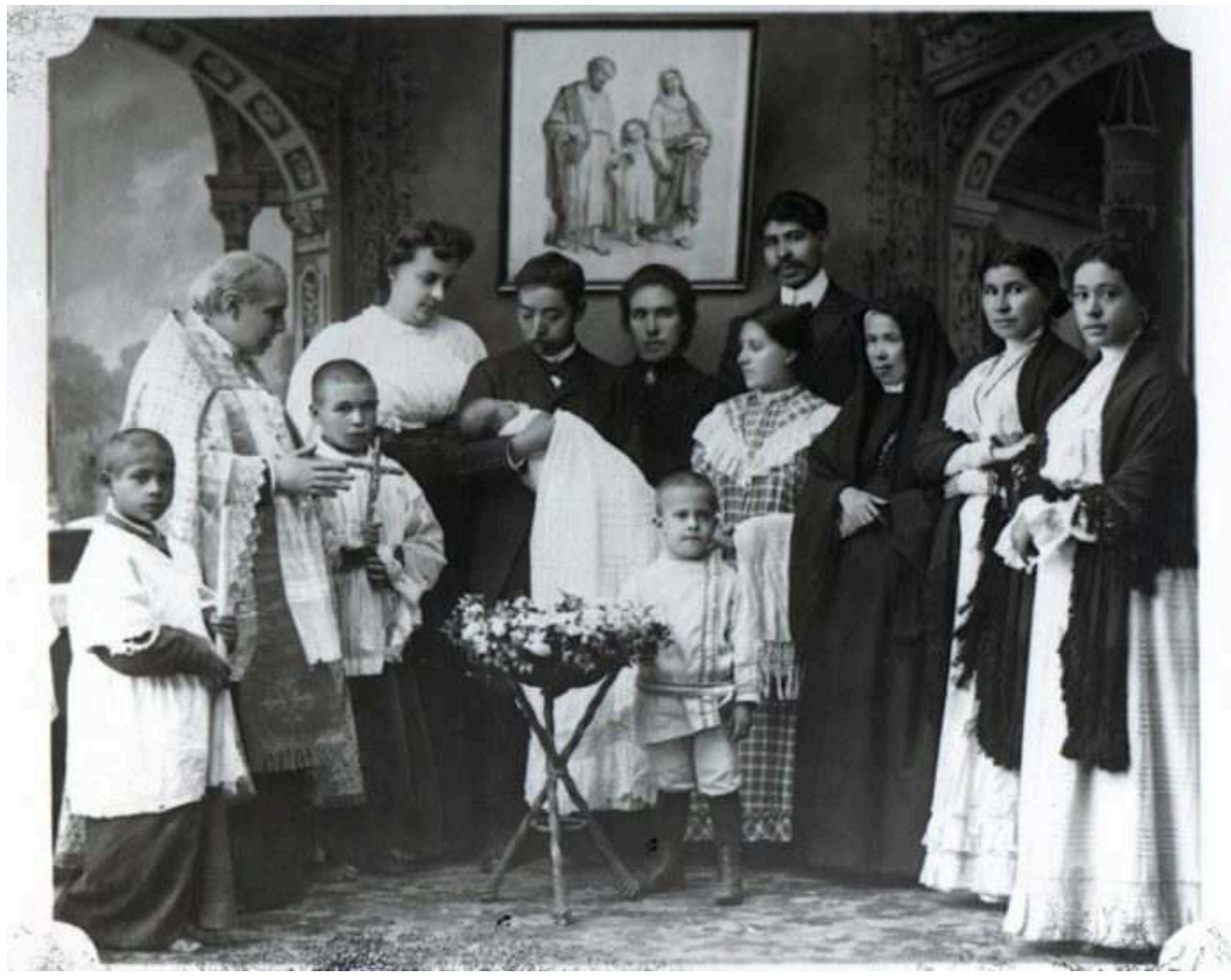

Figura 3: Juan José de Jesús Yas (centro) participando como padrino de bautizo de su sobrino político José Domingo Noriega (1885).24

Fuente: Fototeca CIRMA, presentada como parte de una exposición conmemorativa del centenario del fallecimiento del artista, realizada en el Museo de Arte Moderno de la Ciudad de Guatemala entre finales de 2017 y el 28 de enero de 2018.

https://lahora.gt./centenario-yas-2/ 


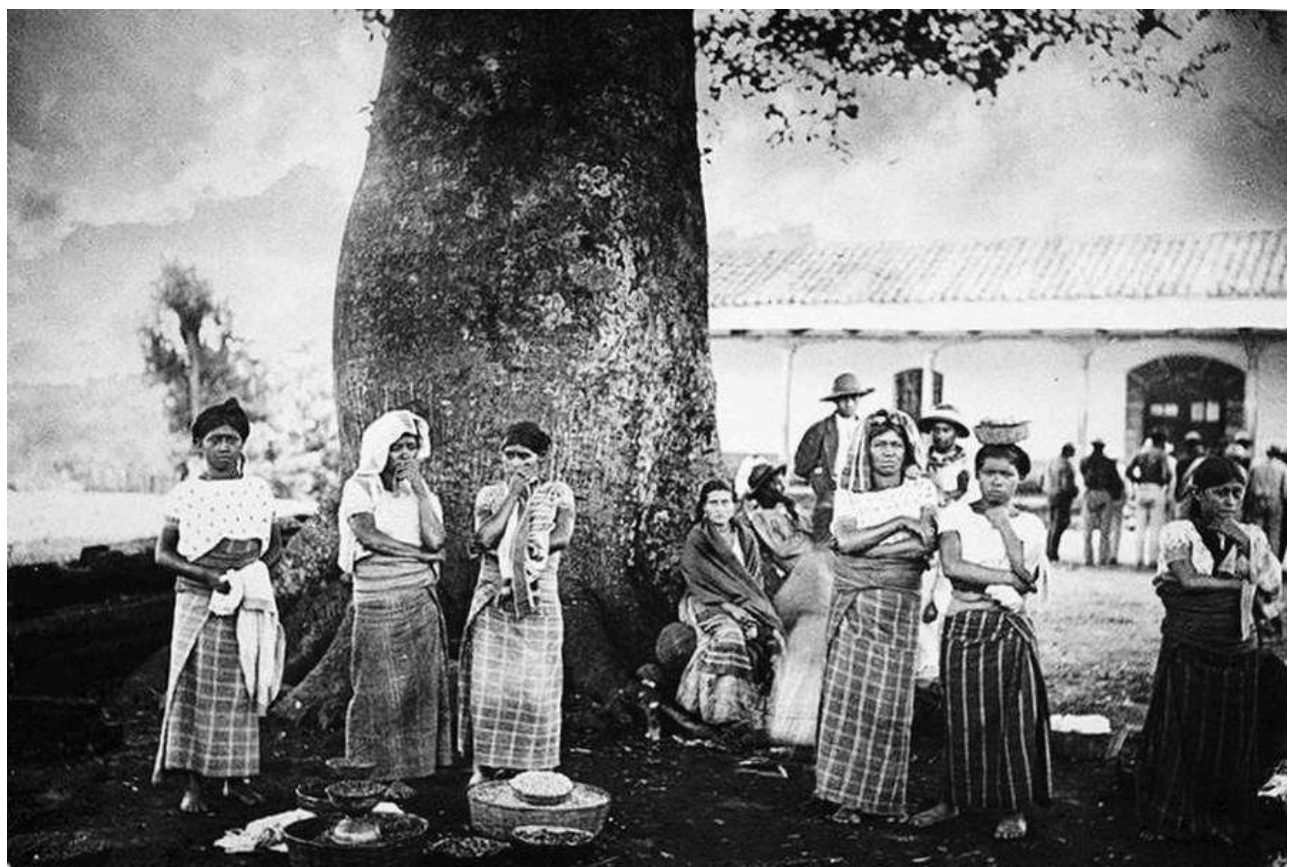

Figura 4: Conjunto de mujeres indígenas de un pueblo del centro de Guatemala, (finales siglo XIX, inicios siglo XIX) Yas supo captar, por medio de este y otros trabajos, instantáneas de contextos cercanos, en tiempo y espacio, a la Antigua Guatemala, ciudad omnipresente en los productos del fotoarte que desarrolló.

Colección "Archivo Privado de Juan José de Jesús Yas" (CIRMA)

Link: https://images.app.goo.gl/EJJvrX91AEEdxqF7

Fuente: Artículo "La fotografía un invento revolucionario", autor Néstor Galicia

Diario Prensa Libre, versión digital del 19 de agosto de 2016, Sección "Hemeroteca"

Link: https://www.prensalibre.com/hemeroteca/176-aos-de-imagenes/

En cierto modo, el ambiente que se representa en la imagen, contribuye a visualizarlo como completamente occidentalizado. Tanto por su vestimenta, que asemeja a la del "formal" o "estilo sastre" del momento, como por el hecho de haberse casado con una mujer nativa, Yas puede contarse como un ciudadano guatemalteco. Su boda es evento que trasciende de la unión marital, generando lazos de parentesco político que le integrarían a un nuevo contexto social. Quizás esto se comprenda mejor asumiendo que, previo a ello, el fotógrafo se había convertido al catolicismo, bautizándose y adoptado un nombre occidental, que conservó hasta su muerte. 


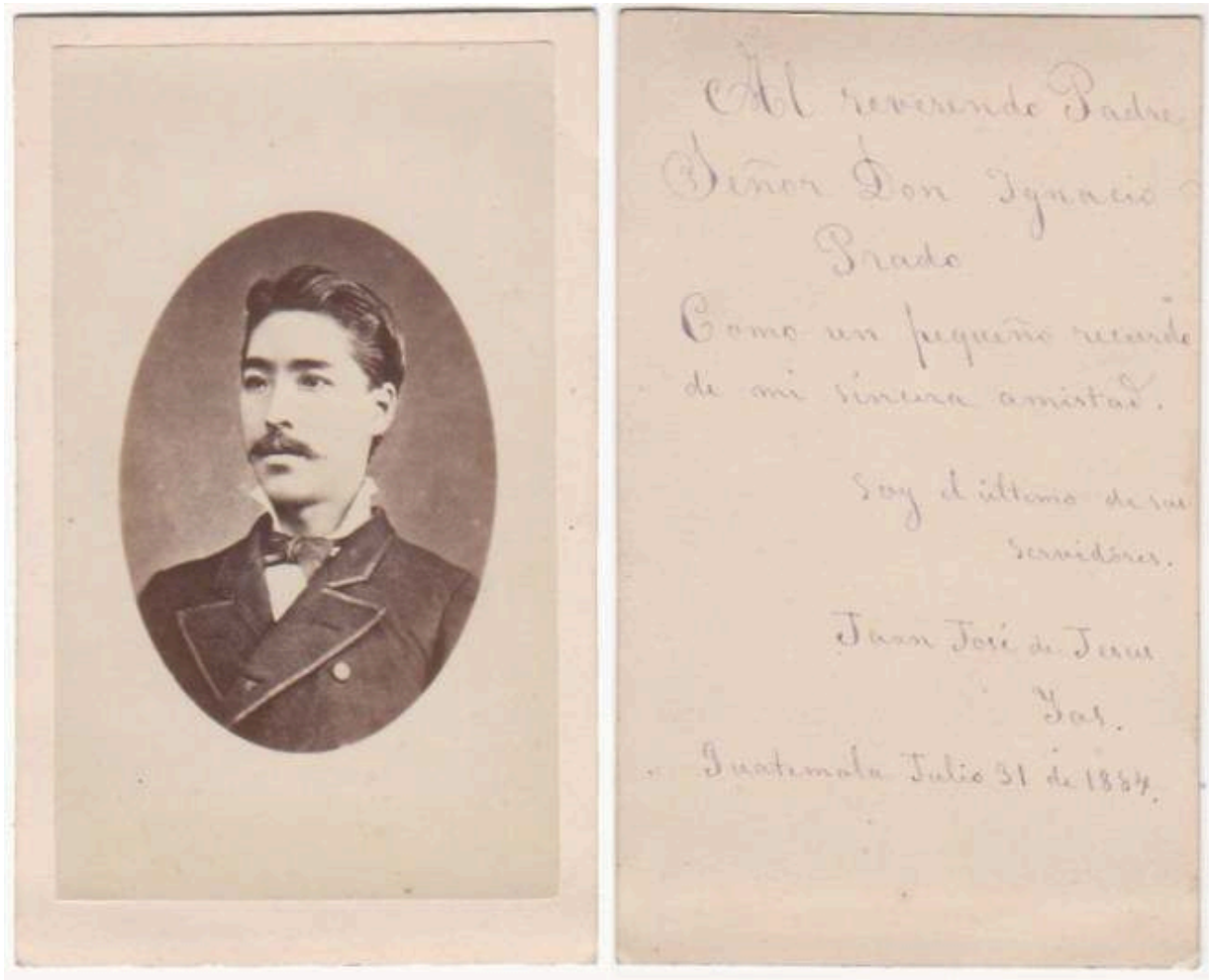

Figura 5: Retrato de Juan José de Jesús Yas con una dedicatoria en su dorso a Ignacio Prado, fechada el 31 de julio de 1884. ${ }^{25}$ Parte de la colección "Archivo Privado de Juan José de Jesús Yas" (CIRMA)

https://images.app.goo.gl/Fhj7fRmuSQWZpvSZA

Fuente: Blog "Los grandes fotógrafos"

Link: https://losgrandesfotografos.blogspot.com/03/juan-jose-de-jesus-has-1856-1917.html?m=1 26

El ligamen con su nuevo contexto tiene su expresión más patente cuando se encuentra que, el heredero universal de los bienes de Yas es el sobrino de María Noriega, el joven José Domingo del mismo apellido a quien llevó al bautismo en la fe católica. Con la transferencia de aprendizajes que ha existido entre ambos, y la fortaleza de este vínculo, el trabajo realizado en el estudio "Fotografía Japonesa" se enriqueció grandemente y perduró varias décadas.

\section{Conclusiones}

57 La inserción del Kohei Yasu (desde 1878 Juan José de Jesús Yas) en la sociedad guatemalteca no se generó como parte de una oleada migratoria o traslación de japoneses en forma masiva a tierras centroamericanas, sino que obedeció a las consecuencias de los conflictos internos entre las élites mexicanas al ser desplazado del poder su protector, el entonces presidente Sebastián Lerdo de Tejada.

Debido a que, la migración japonesa inició precisamente con Kohei Yasu a Centroamérica, no se le puede caracterizar como migrante con objetivos económicos. En su caso, privó como condición para llegar a Guatemala, su involucramiento en el círculo de simpatizantes de un presidente de México, país del que procedieron intelectuales que fueron acogidos por el gobierno liberal guatemalteco y a los que se insertó en procesos de modernización de la educación y la administración pública, como es el caso de José Martí. 
59 Al arribo de Kohei Yasu, la fotografía en Guatemala se hallaba en pleno proceso de desarrollo, evolucionando bajo la impronta del trabajo de fotógrafos estadounidenses y europeos. Algunos de estos arribaron al país llevados por el ímpetu de explorar nuevos contextos en los cuales ejercer su oficio, otros, sobre todo los alemanes, fueron parte de movimientos migratorios apoyados por el gobierno, el cual facilitaba a los súbditos germanos la inversión, estancia y arraigo en base a tratados y acuerdos contraídos con el Imperio Alemán después de 1871. En el caso de los fotógrafos estadounidenses, su entrada al país obedeció al impulso de comprender y conocer los contextos periféricos.

El desarrollo del fotoarte por parte de Juan José de Jesús Yas tuvo varias etapas de maduración, iniciando con su incursión en los talleres fotográficos de Emilio Herbruger padre y Eduardo Kildare, posición en la cual sufrió explotación y escasa remuneración. No obstante, su tenacidad y empuje le permitieron forjarse un lugar en el mercado fotográfico obteniendo, gradualmente, los implementos para establecer su propio estudio, denominado "Fotografía Japonesa".

61 La memoria migratoria de Juan José de Jesús Yas está presente en algunos ejemplares de su fotoarte. En este aspecto, destacan dos creaciones que le muestran participando de una integración a Occidente. Se trata de una fotografía tomada cuando frisaba los cuarenta y tres-cuarenta y cuatro años de edad, en la que se retrató vestido parcialmente con atuendos japoneses (1890) y otra en la cual posó elegantemente después de su boda con la guatemalteca María Noriega (1891).

Ambos ejemplares muestran dos facetas en las que Yas estuvo inmerso y que se reúnen en el hombre que se ve retratado. Una de ellas es la de súbdito japonés, que si bien, obviamente sufre cambios al residenciarse en Guatemala no se pierde del todo, pues representa su origen, la cultura nativa, el contexto de donde surgió, caracterizado por el hermetismo y la resistencia ante las invasiones culturales. Como se sabe, la política aislacionista nipona se reprodujo desde que tuvo lugar la victoria, en 1600, el shogun Tokugawa Ieyasu, quien cerró el país a los extranjeros, prohibiendo a los ciudadanos japoneses abandonar el archipiélago so pena de muerte, así como sostener relaciones o intercambios comerciales, para lo cual, la pena era la misma. La "apertura" que dio inicio a la occidentalización, como se sabe, fue forzada por Estados Unidos, país que amagó el envío de su flota para abrir los puertos en 1853.

La otra faceta del artista, corresponde a la del hombre que se forjó una carrera profesional en Guatemala, a partir de adversidades, con esfuerzo, dedicación y tenacidad, lo cual le llevó a ser propietario de su propio estudio y a desposarse con una mujer de un contexto cultural distinto totalmente al suyo. Estas fotografías muestran una gran versatilidad, aunque se puede afirmar que llegó a desarrollar un peculiar apego a su país de adopción, dado que realizó varios viajes a Japón y a otros países, sin intentar volver a su patria o arraigarse donde existieran mejores condiciones que en Guatemala, donde recaló.

Una vez independizado, Yas protagonizó una evolución creativa en su desempeño como fotógrafo que puede ser catalogado, en gran parte de fotoarte, por cuanto ello evidencia un aprendizaje especial para efectuar las tomas y revelar los negativos. Una revisión a los materiales visuales de su autoría a los que se puede acceder por medio de soportes electrónicos en la actualidad, permite establecer que manejó una extensa gama de tonalidades con base en la técnica del enfoque de tomas con colocación de películas de gelatina sobre láminas de cristal. Ser pionero en esta técnica le confiere, en la 
actualidad, el status de contribuyente con el desarrollo de innovaciones en el arte de la fotografía.

Notas

\section{NOTAS FINALES}

1. Este nombre fue el que adoptó cuando se convirtió al catolicismo previo a casarse con María Noriega en 1891. En el transcurso de la redacción de este artículo, no pudieron obtenerse datos fidedignos acerca de qué confesión religiosa profesó con anterioridad, aunque presumiblemente, como la mayoría de japoneses de entonces, así como de los que vivieron el siglo siguiente, profesó el budismo mahayana complementándolo con la fe Shinto, de orientación naturalista y de culto a los antepasados, promovida por la Casa Imperial como Religión Nacional, siendo un aspecto básico de la misma una creencia en el origen divino del Emperador y su familia, lo que persistió hasta bien entrado el siglo XX. Esto solamente fue descontinuado con la invasión norteamericana iniciada tras la derrota en la Segunda Guerra Mundial en 1945. Después de ello, con la secularización de lo público, ha aumentado en los conteos estadísticos la cifra de no religiosos. (nota del autor)

2. La estructura de los mismos destaca la contribución de ambos artistas como puede notarse en los títulos: “Apuntes sobre fotografía en Guatemala: Juan J.J. Yas y Domingo Noriega" publicado en 1982 con ocasión de un homenaje a la memoria de los dos fotógrafos, como los desarrollados en 2017 y “Juan José de Jesús Yas y José Domingo Noriega 1880-1960". El cierre de los centros de documentación por la pandemia de Covid-19 impidió una búsqueda de estos materiales, los cuales no se encuentran en formato electrónico.

3. La antropóloga taiwanesa Pi-Heng Chen ha aportado en años recientes una gran contribución al respecto con un trabajo investigativo que se ha materializado en artículos y exposiciones, basando también la investigación para obtener el grado de $\mathrm{PhD}$ en una disertación sobre la vida y trabajo de Kohei Yasu. En Guatemala, este es el segundo trabajo de carácter académico al respecto. Para articular la parte inicial del se han tomado datos sobre la vida del fotógrafo, los que fueron incluidos en proemios de algunos artículos periodísticos difundidos en el año 2017, cuando se realizaron exposiciones fotográficas de la obra del artista rememorando el centenario de su fallecimiento, ocurrido en la ciudad de Antigua Guatemala.

4. Este dato añade otra fecha de nacimiento para Kohei Yasu, pues si su fecha de nacimiento era en el mes de julio, cumplió 22 años sirviendo en la campaña concluida en 1868; puede asumirse entonces que nació en 1846, como lo establece Ping-Heng Chen.

5. Este fue un viaje sumamente largo, en el que, para llegar al destino final, el vapor recaló en China, India, Arabia y se dirigió a Europa cruzando el recién abierto Canal de Suez, llegando el 18 de marzo a Nápoles, recorriendo más de 5,000 kms., toda una odisea en la era de viajes intercontinentalesen buques de vapor. Como su principal destino en Europa era Francia, llegó a París el 9 de abril, permaneciendo ahí cinco meses y medio.

6. Barrios era un hijo de pequeños terratenientes del pueblo de San Lorenzo, departamento de San Marcos, se graduó como abogado graduado en la Universidad de San Carlos. Descolló como líder militar a momento de que la alianza liberal produjo los primeros movimientos contra el gobierno conservador de Vicente Cerna y Cerna, gobernante desde 1865 a la muerte de Rafael Carrera y Turcios, presidente vitalicio en 1854. García Granados, de origen gaditano por el lado 
paterno, provenía de una familia de comerciantes y militares que desertó del bloque en el gobierno con el fraude electoral de 1869 que perpetuó a Cerna. Ambos fueron favorecidos por el gobierno mexicano, el cual hacía caso omiso de las incursiones de Barrios y de Serapio Cruz, otro caudillo liberal, hacia Chiapas para refugiarse de la persecución de las tropas gubernamentales. Al mejor estilo de las guerrillas, Barrios y Cruz lograron desgastar a las tropas del gobierno, al punto de que, cuando García Granados compró fusiles Remington en Estados Unidos y los llevó a Guatemala a través de México con la venia de Benito Juárez, las tropas del gobierno cayeron derrotadas rápidamente ante el poder de fuego de armas modernas. La remembranza de ese triunfo subsiste, simbólicamente, en el Escudo de Armas del país, exhibido en la Bandera Nacional actual. Después del triunfo liberal, la persecución de partidarios de los conservadores constituyó el pretexto para la expansión de la Reforma a través de la guerra, lo que llevó a conflictos con El Salvador y Honduras entre 1872 y 1876, instalando en el poder ahí a partidarios de la reforma liberal que llevaron a cabo la expansión de este movimiento modernizador.

7. Estado infraestructural que documentaron algunos viajeros norteamericanos como John Lloyd Stephens, que arribó al país en 1837, holandeses como Jacobo Haefkens, cónsul de los Países Bajos ante la República Federal de Centroamérica (1824-1838), o franceses, en el caso de Arthur Morelet, quien visitó al país bien entrado el siglo en el apogeo del gobierno conservador de Rafael Carrera.

8. En ese momento, el único ramal ferroviario existente, era el inaugurado por los conservadores, que comunicaba desde 1869 el pueblo de Amatitlán con la ciudad de Guatemala.

9. Hijo de Justo Rufino Barrios, abatido junto a él en un confuso incidente ocurrido en abril de 1885 pocos kilómetros dentro del territorio salvadoreño cuando el guatemalteco trataba de unificar, por la fuerza, a los países que antiguamente constituyeron la República Federal de Centroamérica (Guatemala, El Salvador, Honduras, Nicaragua y Costa Rica) en una nación gobernada por él según el decreto del 28 de febrero del año citado.

10. La ciudad de Guatemala está dividida actualmente, en zonas numeradas, originalmente, del 1 al 21, a las cuales se les ha añadido la 24 en los últimos años. Esto obedece al ordenamiento realizado por el ingeniero Raúl Aguilar Batres, destacado urbanista que formuló una estructura partiendo de asumir el actual centro histórico, correspondiente al casco viejo, como la "zona 1", una especie de "kilómetro cero" como se observa en París y Ciudad de México- y asignando a sectores colindantes por los cuatro puntos cardinales, los números 2, 3, 4, y 5, reproduciendo un trazado ajedrezado imaginario, siguiendo una dirección en sentido inverso a las manecillas del reloj. Después del último número, siguen el 6,7,8 y 9, y así, sucesivamente hasta llegar a 19, lo que expandió la zona urbana hacia el municipio de Mixco. La zona 21 fue agregada modernamente con la urbanización de sectores como Nimajuyú, originalmente dedicados a la construcción de multifamiliares y la 24 se estableció en inmediaciones de las 17 y 18 . Existe en la actualidad, a modo de "leyenda urbana", la suposición de que la zona 20, inexistente, fue ocupada por el Cementerio General, ubicado en la zona 3. (nota del autor)

11. Esto tuvo lugar en gobierno del general José María Reyna Barrios (1892-1898), continuador de la política de García Granados de creación de símbolos patrios.

12. Se sabe también de la existencia de trabajadores hindúes en Panamá hacia mediados de siglo, así como de del exilio de algunos cientos de rebeldes que participaron en el motín de los cipayos de 1857 en la actual Belice, antes Honduras Británica. La presencia de estos en el istmo obedeció a los primeros intentos de establecer un canal interoceánico. Centroamérica recibió a migrantes laborales hindúes después, cuando la abolición de la esclavitud africana en las Antillas inglesas en 1834 hizo posible la importación de braceros de otras colonias, de las cuales la India fue uno de los principales lugares de reclutamiento.

13. La región la componen, actualmente, los departamentos de la zona occidental: Quetzaltenango, Totonicapán, Quiché, Suchitepéquez, Sololá, Retalhuleu, San Marcos y Huehuetenango. Antes de la independencia, en 1821, tuvo lugar en el segundo de ellos una 
asonada autonomista dirigida por el noble de etnia quiché Atanasio Tzul y, la ciudad de Quetzaltenango fue, en 1838,1840 y 1848, epicentro de un movimiento separatista que procuró la separación y emancipación de Guatemala, conformando el Sexto Estado de la Unión Centroamericana con los departamentos señalados.

14. Yas volvió a Japón “después de quince años de partir”. La prioridad de este viaje era visitar a su familia, como lo muestra Escobar transcribiendo notas de su diario: "Después de ausentarme durante 15 años, gracias a Dios, como a las 11 de la noche, llegamos al puerto de Yokohama. El día 30, a las cinco y media, salí en ferrocarril a Tokio y llegué a las seis con cinco minutos". Debió poseer una preocupación especial por su madre, pues manifestó: "La encontré buena y estuvimos viviendo muy contentos en Tokio, en el cantón Tsukiji, cerca de la catedral de los misioneros, en una casita muy cómoda, en compañía de mi sobrina Tamaki".. Como puede notarse, el ligamen que obtuvo con la Iglesia Católica le fue útil en ese viaje, del cual no regresó directamente a Guatemala, sino que fue a Perú como ingeniero de minas, a pedido de un ejecutivo de una empresa dirigida por japoneses, a quien acompañó no sin antes hacerle énfasis que había llegado de nuevo a Japón para reunirse con su madre: "Me rogó mucho para que yo lo acompañara y le contesté que no podría disponer sin consentimiento de mi madre, porque me había ausentado mucho tiempo, dejándola abandonada", "Finalmente ella consintió, obligándome a aceptar. Sin mucha voluntad la tuve que dejar, me despedí de ella con mi alma llena de tristeza". . Decidiendo ir a Sudamérica, emprendió un viaje en el que hizo una escala en el país de donde ya era ciudadano, mostrándolo melancólicamente en su diario: (...) “Anoche no pude cerrar mis ojos por la alegría que sentía de ver pronto a mi querida e inolvidable Guatemala, pues decidí hacer un viajecito a la capital con el mayor gusto de saludar a mis amigos", lo que se complementa con otra nota más confidencial en la que expresó su sentir cuando su nave zarpó de costas guatemaltecas: "bajé a mi camarote, a llorar, solo"

15. Me refiero al apellido Yax, Jash o Jax, presente en las tierras altas de Guatemala, como uno muy parecido al que adoptó el japonés, Yaxón. De hecho, muchos apellidos indígenas de esta región, habitadas los pueblos quiché, cakchiquel y tzutuhil, mismos que tienen resonancia oriental, especialmente china y coreana como Chaj, Chin, Chon, Alay, Chay, Lux, Say, Choy, Coc, etc., lo que también se encuentra en la región vecina de las Verapaces, donde se evidencia lo mismo con los apellidos Sam, Caal, Maas, Pop, etc.

16. Yas deseaba entonces visitar a su familia en Japón. Ello requería de dinero, el cual no pudo obtener de su trabajo con su primer patrón. He aquí la explicación en sus palabras transcritas por el periodista guatemalteco José Luis Escobar: "Me decidí pasar con el señor Kildare porque no me alcanzaba para el gasto ordinario con lo que me pagaban, mucho menos para juntar el dinero para mi viaje a Japón, aunque estuviera trabajando mil años con él (Herbruger). Como no me adelantaba la suerte, reflexioné que no podría hacer nada si no lo hacía de manera independiente. Poco a poco conseguí las máquinas y los demás útiles".

17. Cuando las mismas ingresaron a dichos fondos documentales, las autoridades intuían la ausencia de piezas valiosas, como 37 pertenecientes a la colección privada de Yas, en poder de Luis Luján Muñoz, de las cuales el centro de documentación logró obtener reproducciones.

18. Realizo estas precisiones para dejar asentado que, la existencia de los mecanismos y procesos tecnológicos que permiten la existencia de las fotografías, ya en formato físico o digital, es un producto social en el que intervienen múltiples mediaciones y se integran variados aportes científicos y tecnológicos. Lo resalto debido a que, aún persiste la tendencia a omitir este elemento sumamente importante en el conocimiento y socialización de los contenidos a escala ampliada. Esto lo puedo ejemplificar, más elocuentemente, de la forma siguiente: Puedo pensar que, una fotografía en la que estoy retratado junto e mi familia nuclear es completamente y totalmente privada, patrimonio familiar y por tanto, negarme a escanearla para compartirla con otros familiares residentes en el extranjero o con amistades, por el hecho de que la asumo como "privada" per se y así debe quedar por siempre y para siempre. Empero, aun pensando así, la fotografía en cuestión, pese a todo lo que yo sostenga, presentando múltiples argumentos en 
favor de la exclusividad antes detallada es, finalmente, producto, consecuencia y resultado de los citados procesos de industrialización, trabajo y socialización que hicieron posible, me fotografiaran con mis familiares en un momento dado. La privacidad y exclusividad que brinda la propiedad sobre una fotografía, aún con su carga afectiva, no exime a la misma de ser un producto social, como todos los adelantos tecnológicos.

19. Aunque, claro está, atendiendo a las interpretaciones universalmente difundidas de Vladimir I. Lenin e Immanuel Wallerstein, el sistema capitalista (el único que ha alcanzado una dimensión global) no presenta uniformidad, siendo solamente los países puntales, las potencias en los aspectos económico y tecnológico, en los que se observa el mayor desarrollo y expansión de la producción de mercancías e introducción de nuevos usos y hábitos de consumo de la masa de consumidores.

20. La diferencia entre fotografía y fotoarte reside en una valoración estética del discurso visual. Una toma fotográfica aleatoria, sin mayor énfasis estético, con la cual se pretende "capturar" un momento determinado para posterizarlo sin mayor preocupación del formato, color, luz, sombra etc. es fotografía, así de simple y llano. Caso contrario, cuando quien ejecuta la toma tiene una intencionalidad manifiesta de lograr cierto refinamiento formal, acrecentando el énfasis en lo visual, perfeccionando al máximo tanto la técnica de iluminación, captura y revelado, así como los arreglos previos a la toma, concentrando energía y recursos en lograr la mejor calidad estética posible, ya puede ser reconocida como fotoarte.

21. Esta fotografía captura un momento de la proyección de Yas como modelo fotográfico así como también involuntario documentalista del desarrollo de la fotografía en Guatemala. Aunque la misma no encaja como un material relacionado directamente con su migración al país, testifica de forma elocuente la confluencia de elementos culturales que configura un discurso visual de encuentro entre su identidad japonesa, el mundo del cual es una especie de "embajador" y la versión de la cultura occidental desarrollada en un país periférico. El sombrero que luce en ella no podría calificarse como parte de una indumentaria asiática, asemejándose más a un casco que a un sombrero en el sentido estricto, pues carece de alas y copa. La bata con que posa es calificada como un kimono en el catálogo del Centro de Investigaciones Regionales de Mesoamérica (CIRMA).

22. La pose en la que se mostró Yas guarda paralelismo con una de las fotografías que se han conservado del primer y único presidente vitalicio del país, el General José Rafael Carrera y Turcios, aliado de la Iglesia y la oligarquía, así como enemigo acérrimo de los liberales. La similitud existe en colocar la mano derecha sobre una columna como la que aparece en el caso del fotógrafo nacido en Japón, una curiosa coincidencia, sobretodo sabiendo que él llegó a Guatemala durante el apogeo de la hegemonía liberal.

23. Una observación detallada de la vestimenta de Yas en esta fotografía deja entrever que no viste totalmente la indumentaria de un varón guatemalteco urbano de clase media. El cuello de su camisa deja entrever una influencia de la tendencia "a la china", lo que podría expresar una reminiscencia oriental confluyendo en la chaqueta que viste en su matrimonio con María Noriega.

24. La participación como padrino de su sobrino evidencia el uso de la entrada en el catolicismo de Yas como mecanismo de integración en la sociedad guatemalteca.

25. El acento comedido y evidentemente caballeresco en el cual Yas expresa su adhesión al personaje mencionado en el dorso, resulta usual en el contexto de relaciones que sostuvo con miembros de la sociedad guatemalteca de fines del siglo XIX. Sin embargo, la expresión "el último de sus servidores" manifiesta, de cierta forma, la actitud solícita de un japonés promedio en tiempos del antiguo régimen, caracterizado por la servidumbre del campesinado y la subordinación extremadamente leal de la casta samurái a los señores feudales. 
26. En los datos de este enlace se aprecia como fecha aceptada para el nacimiento de Yas el año de 1856, lo que contrasta con la versión presentada por algunos interesados, que lo asumen nacido más de diez años antes, en diciembre de 1844.

\section{RESÚMENES}

Este artículo presenta, en primera instancia un resumen de los principales datos biográficos de Kohei Yasu, un astrónomo y viajero japonés que se residenció casi ininterrumpidamente en Guatemala entre 1877 y 1917. Seguidamente, se establece cuál fue el panorama político del país al momento de su llegada e inserción, enfatizando en que, recientemente, se habita instalado un nuevo equilibrio de poder en el que habían accedido a sitial hegemónico grupos emergentes de ideología liberal, cuyas políticas favorecieron la migración. A continuación, se examinan las condiciones particulares del desarrollo del arte fotográfico de Kohei Yasu a través del estudio "Fotografía Japonesa", la cual marca una impronta en el fotoarte guatemalteco, con gran participación de expertos alemanes y de otras naciones europeas a fines del siglo XIX y principios del XX. .

Cet article commence par un résumé des aspects biographiques de Kohei Yasu ou de Juan José de Jesús Yas, un photographe de renom d'origine japonaise arrivé au Guatemala en provenance du Mexique en 1877. Nous décrirons examiner les conditions particulières du développement de l'art photographique développé par Kohei Yasu, à travers l'atelier "Fotografía Japonesa", qui marque avec son empreinte la photographie d'art guatémaltèque, avec une grande participation d'experts venus de l'Allemagne et d'autres nations européennes.

\section{ÍNDICE}

Palabras claves: discurso visual, fotoarte, Juan José de Jesús Yas, Kohei Yasu, migración.

Mots-clés: discours visuel photographie d'art, Juan José de Jesús Yas, Kohei Yasu, migration.

\section{AUTOR}

\section{NÉSTOR FELÍCITO VÉLIZ CATALÁN}

Universidad de San Carlos.

Ciudad de Guatemala (1979), Profesorado en Historia y Ciencias Sociales (2006),

Coordinación video documental "Kaminal Juyú ayer y hoy su importancia como fuente histórica, arqueológica y recurso pedagógico” link: https://www.youtube.com/watch? v=59docMGh5iI 2016, Participación online en el III Congreso Internacional de Historia de América, INAH, México 2017. Segundo lugar concurso de ensayo “Antonio Goubaud Carrera", Guatemala 2019. 